\title{
Novel technique for treating intussuscepted intestinal Meckel's diverticulum: enteroscopic intestinal diverticulum dissection (EIDD)
}

Meckel's diverticulum is a well-described anomaly of the small intestine caused by the incomplete closure of the omphalomesenteric or vitelline duct. It generally does not cause any symptoms [1]. Treatment is usually performed for complications, the most serious being gastrointestinal bleeding. Traditional treatments including diverticulum exclusion, varus suture, simple resection of the diverticu- lum, and partial resection of the small intestine, are traumatic [2,3]. Enteroscopic surgery is a recently developed treatment modality. Herein, we report on a novel technique, called enteroscopic intestinal diverticulum dissection (EIDD) ( Fig. 1), for treatment of intussuscepted intestinal Meckel's diverticulum.

A 30-year-old woman complained of tenderness in the lower abdomen. Con- trast-enhanced computed tomography showed a long intussuscepted diverticulum. Double-balloon enteroscopy at our hospital located a $10-\mathrm{cm}$ pedunculated mass protruding into the intestinal cavity, with an umbilicate depression at the center of the head of the mass. Two metallic clips were placed at the base of the diverticulum for future location. Two weeks later, symptoms remained and the pa-

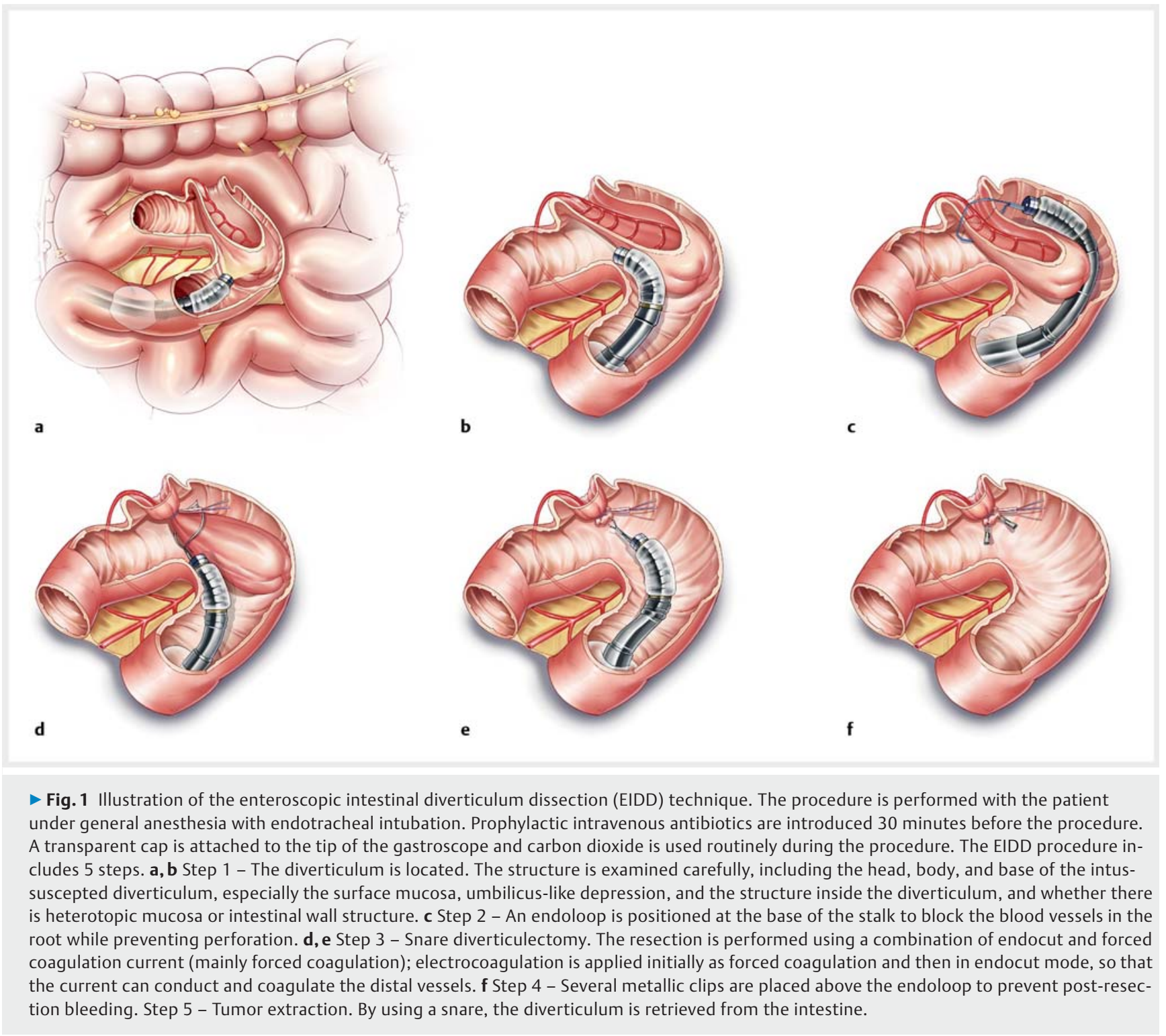



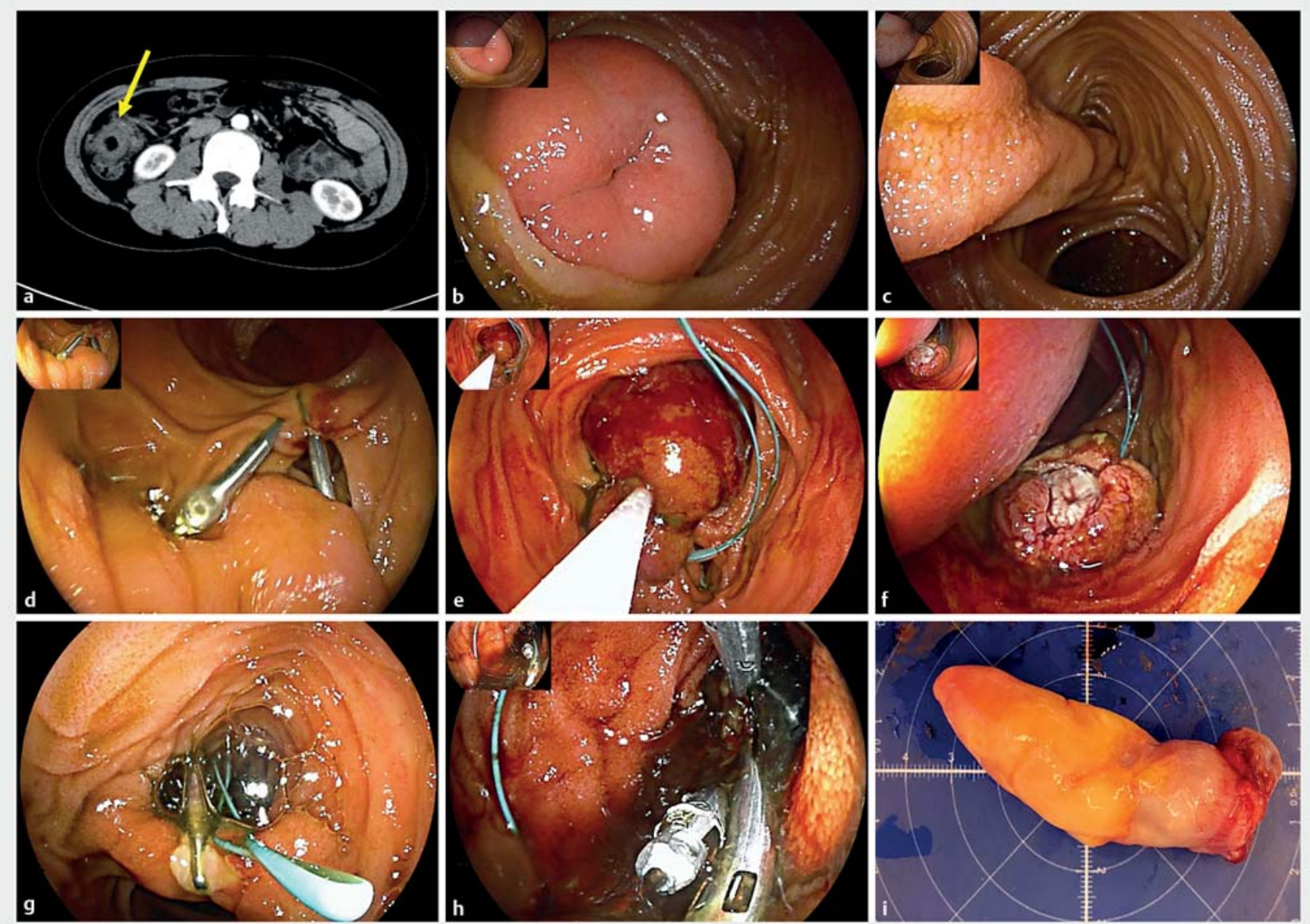

- Fig. 2 Enteroscopic intestinal diverticulum dissection for the treatment of occult gastrointestinal bleeding caused by intussuscepted Meckel's diverticulum in a 30-year-old female patient. a Computed tomography showed a sheath-like structure. $\mathbf{b}, \mathbf{c}$ Visualization of an inverted Meckel's diverticulum $100 \mathrm{~cm}$ from the ileocecal valve. $\mathbf{d}$ Location site. e The endoloop around the stalk. $\mathbf{f}$ Snare diverticulectomy. $\mathbf{g}$ Diverticulum inversion. $\mathbf{h}$ Hemoclips at the stalk. $\mathbf{i}$ Finger-like specimen: $7 \times 2 \times 2 \mathrm{~cm}$ in size.

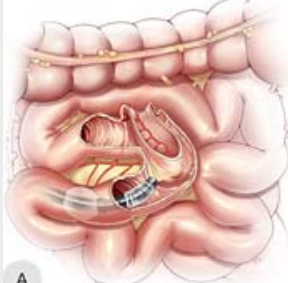

A

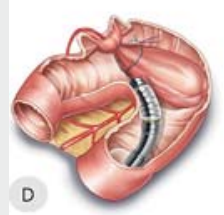

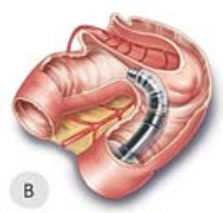
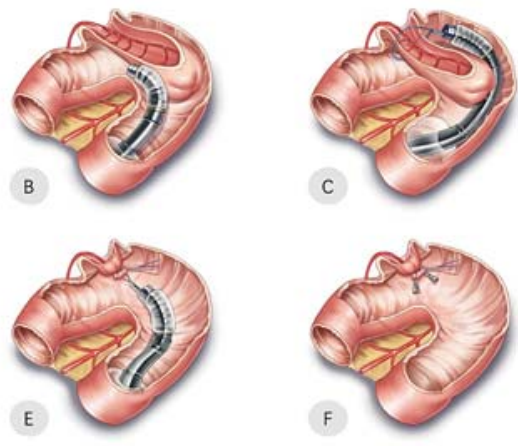
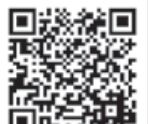

$\checkmark$ Video 1 Enteroscopic intestinal diverticulum dissection for the treatment of intussuscepted Meckel's diverticulum in a 30-year-old female patient, with successful therapeutic double-balloon enteroscopy and an operative time of 40 minutes. The morphology showed a finger-like mass, $7 \times 2 \times 2 \mathrm{~cm}$ in size. Histologic examination showed that the diverticulum was composed of heterotopic pancreatic tissue. tient opted for endoscopic treatment. The EIDD technique, which is applied in large pedunculated polyps, was performed and complete resection of the diverticulum was achieved, thus avoiding surgery ( $\triangleright$ Fig. 2 , \ Video 1 ). The postoperative course was uneventful. The patient was discharged 3 days after enteroscopic surgery. Her symptoms resolved completely during follow-up.

When considering EIDD, we should ensure that the diagnosis is clear preoperatively to exclude intestinal duplication, polyp, submucosal tumor, or intestinal wall varus. Standardization of the procedure should be established by constant accumulation and review of experience, including choice of instruments, method of resection, suture techniques, and so on. In this way, enteroscopic treatment can maintain intestinal integrity and lead 
to rapid healing, free of postoperative adverse events, especially anastomotic complications. Further clinical studies with a larger number of patients are necessary to confirm this hypothesis.

Endoscopy_UCTN_Code_TTT_1AP_2AD

\section{Acknowledgement}

This study was supported by grants from the National Natural Science Foundation of China (81902394), Shanghai Dawnlight program (20CG07), and Excellent Young Scholar Foundation of Zhongshan Hospital (2021ZSYQ08).

Funding

National Natural Science Foundation of China

http://dx.doi.org/10.13039/

501100001809

81902394

Shanghai Municipal Education Commission http://dx.doi.org/10.13039/

501100003395

20CG07

Zhongshan Hospital

http://dx.doi.org/10.13039/

501100010108

2021ZSYQ08

\section{Competing interests}

The authors declare that they have no conflict of interest.

The authors

\section{Ping-Ting Gao, Meng-Jiang He, Quan-Lin Li,} Ping-Hong Zhou, Li-Li Ma

Endoscopy Center and Endoscopy Research Institute, Zhongshan Hospital, Fudan University, Shanghai, China.

\section{Corresponding author}

\section{Li-Li Ma, MD}

Endoscopy Center and Endoscopy Research Institute, Zhongshan Hospital, Fudan University, 180 Fenglin Road, Shanghai 200032, China

enteroscopy@126.com

\section{References}

[1] Park J], Wolff BG, Tollefson MK et al. Meckel diverticulum: the Mayo Clinic experience with 1476 patients (1950-2002). Ann Surg 2005; 241: 529-533

[2] Takagaki K, Osawa S, Ito T et al. Inverted Meckel's diverticulum preoperatively diagnosed using double-balloon enteroscopy. World J Gastroenterol 2016; 22: 4416-4420
[3] Uchiyama S, Sannomiya I, Hidaka $\mathrm{H}$ et al. Meckel diverticulum diagnosed by doubleballoon enteroscopy and treated laparoscopically: case report and review of the literature. Surg Laparosc Endosc Percutan Tech 2010; 20: 278-280

\section{Bibliography}

Endoscopy 2022; 54: E578-E580

DOI 10.1055/a-1704-6783

ISSN 0013-726X

published online 21.12.2021

(c) 2021. Thieme. All rights reserved.

Georg Thieme Verlag KG, Rüdigerstraße 14,

70469 Stuttgart, Germany

\section{ENDOSCOPY E-VIDEOS}

https://eref.thieme.de/e-videos

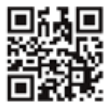

Endoscopy E-Videos is an open access online section, reporting on interesting cases

and new techniques in gastroenterological endoscopy. All papers include a high quality video and all contributions are freely accessible online. Processing charges apply (currently EUR 375), discounts and wavers acc. to HINARI are available.

This section has its own submission website at

https://mc.manuscriptcentral.com/e-videos 